\title{
CLOSURE WITH BRONCHIAL WALL FLAP AND OMENTAL PEDICLE OF DEFECT CAUSED BY DEHISCENCE OF TRACHEAL SUTURE LINE AFTER EXTENDED RIGHT UPPER SLEEVE LOBECTOMY
}

\author{
Takashi Suzuki, MD, Shuichi Suzuki, MD, Yoshito Kamio, MD, and Goichi Hori, MD, Yokohama, Japan
}

One of the most serious complications of tracheal and bronchial reconstruction is dehiscence involving such a large area that no method can ensure reliable repair. We encountered such a case after performing a right upper sleeve lobectomy with right tracheal lateral wall resection. We repaired the tracheal defect with the wall of the lower lobe bronchus, which we had to resect when the right completion pneumonectomy was performed. In addition, we used a pedicled omental flap. After the completion pneumonectomy with the bronchial wall patch for the tracheal defect, the patient's progress has been uneventful for $11 / 2$ years.

A 71-year-old man underwent extended right upper sleeve lobectomy for lung cancer that had invaded the main bronchus and the lower trachea. The first pair of frozen-section specimens taken from the tracheal and bronchial walls at operation found to contain tumor. The tracheal wall was therefore resected from the carina up to the side wall of the fourth tracheal ring.

From the Department of Thoracic and Cardiovascular Surgery, Showa University Fujigaoka Hospital, Yokohama, Japan.

Received for publication March 4, 1996; accepted for publication March 18, 1996.

J Thorac Cardiovasc Surg 1996;112:1116-7

Copyright (C) 1996 by Mosby-Year Book, Inc.

$0022-5223 / 96 \$ 5.00+0 \quad \mathbf{1 2 / 5 4 / 7 3 5 3 3}$
Distally, the resection extended to the ramification of the middle and lower lobe bronchi. The difference in caliber between the two anastomotic sites was large, as was the distance between the highest portion of the tracheal opening and the proximal end of the distal bronchus. We sutured the upper portion of the tracheal defect transversely to reduce the caliber of the tracheal opening and to anastomose the upper part of the tracheal orifice to the distal bronchus. The new tracheal orifice was then anastomosed to the bronchus intermedius. After the operation, there were no clinical findings suggesting complications. Bronchoscopy performed on the seventeenth postoperative day, however, revealed dehiscence on the proximal suture lines (Fig. $1, A$ ).

A second thoracotomy was performed after the bronchoscopy. No purulent fluid was seen. After meticulous dissection of the hilar pleura, however, dehiscence of the suture line became evident, in association with a small abscess. Three options were considered for repair of the defect. The first was to reanastomose both suture lines after debridement. It was thought, however, that this would increase tension on the new suture line. The second alternative was to perform a right completion pneumonectomy, which would primarily close the defect of the lower trachea after debridement. It was feared, however, that this would produce stenosis because this repair would require narrowing the tracheal wall. We therefore chose a third option. A few sutures

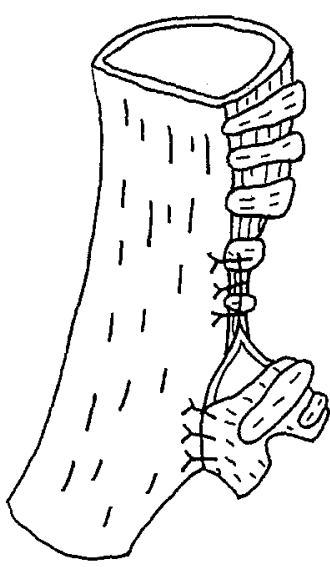

A

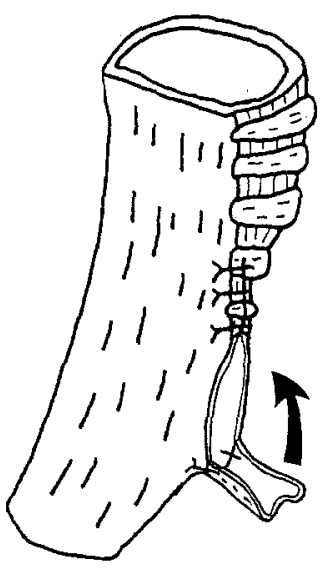

B

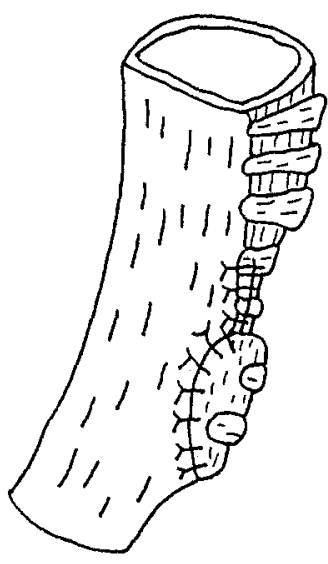

C

Fig. 1. A, Oblique posterior view. Dehiscence of anastomosis of lower tracheal wall and bronchus intermedius. B, Trimmed flap made from lower-lobe bronchus was preserved with a few remaining sutures to trachea. C, Bronchial flap was turned upward and sutured to defect on lower lateral wall of trachea. 
of the bronchial wall of the lower lobal bronchus, which had been sutured to the carina, were removed, and the tissue was trimmed appropriately before the completion pneumonectomy (Figure $1, B$ ). The resulting flap was turned upward and used as a patch for closure of the tracheal defect (Fig. 1, C). We feared that the turned-up bronchial patch would not have sufficient blood supply from the carina through the area of the first sutures, so an omental pedicle was brought up substernally and placed to reinforce the patch and surrounding tissues.

Serial bronchoscopy revealed no complications of the suture line, and the grafted bronchus looked normal. The patient had an uneventful postoperative course for about $11 / 2$ years.

Tracheobronchoplasty occasionally entails problems in anastomosis, especially when the area of resected tissue is quite large. If in such cases dehiscence of the suture line occurs, repair of the tracheobronchial wall becomes more difficult because of the limited tissue available. Mathisen, Grillo, and Vlahakes ${ }^{1}$ reported the use of omentum in complicated thoracic problems, where it induces neovascularity and healing of the infected wound. Our patient required both of these capabilities, promotion of neovascularity of the graft patched over the defect and treatment of the intrathoracic infection caused by the dehiscence. There have been reports on a number of different patches, such as skin, pericardial tissue, and perichondrium, to close tracheal or bronchial defects. Pedicled pericardial flaps were advocated by Smolle-Jüettner and colleagues ${ }^{2}$ for closure of bronchial defects. The patients in that series, however, underwent primary operations and had no coexisting inflammation. A pericardial flap alone might not control infection around a dehiscence. Because our patient had accompanying local infection, an omental flap was necessary, regardless of the type of patch chosen. The bronchial patch was considered the best choice because it has been shown that mucociliary epithelium of the graft is preserved and regenerates after autotransplantation. ${ }^{3}$ Experimentally, tracheal autografts with omental flaps have also been proved reliable when used in pigs and dogs., ${ }^{4,5}$

To our knowledge, there have been no clinical reports demonstrating the efficacy of an autograft of the bronchus and an omental flap to patch a tracheal defect. The procedure described here may be applied in operations for cancer involving the trachea or the main bronchus but without tumor at the level of the lobar or segmental bronchi.

\section{REFERENCES}

1. Mathisen DJ, Grillo HC, Vlahakes GJ. The omentum in the management of complicated cardiovascular problems. J Thorac Cardiovase Surg 1988;95:677-84.

2. Smolle-Jüettner FM, Pinter $H$, Pongratz $G$, Ratzenhofer B, Popper H, Friehs $G$. Closure of bronchial defects using a pedicled pericardial flap. Ann Thorac Surg 1993;56:923-6.

3. Inayama $Y$, Tomiyama I, Akaike $M$, Kase $M$, Nakayama $H$, Morohosi $\mathrm{T}$, et al. Morphologic alterations and cytokinetic studies of tracheal autograft epithelium in rabbits. Ann Thorac Surg 1995;60:952-7.

4. Messineo A, Filler RM, Bahoric B, Smith C, Bahoric A. Successful tracheal autotransplantation with a vascularized omental flap. J Pediatr Surg 1991;26:1296-300.

5. Morgan E, Lima O, Goldberg M, Ferdman A, Luk SK, Cooper JD. Successful revascularization of totally ischemic bronchial autografts with omental pedicle flaps in dogs. J Thorac Cardiovasc Surg 1982;84:204-10.

\section{PERICARDIAL PATCH AUGMENTATION OF THE TISSUE-DEFICIENT MITRAL VALVE IN COMMON ATRIOVENTRICULAR CANAL}

Jacques A. M. van Son, MD, PhD, Richard Van Praagh, MD, Volkmar Falk, MD, and Friedrich W. Mohr, MD, Leipzig, Germany, and Boston, Mass.

Management of the mitral valve is the most critical component of the repair of common atrioventricular canal (CAVC). ${ }^{1,2}$ Patients with normal karyotype have a significantly higher reoperation rate for postoperative mitral

From the Herzzentrum, University of Leipzig, Leipzig, Germany, and the Departments of Pathology and Cardiology, Children's Hospital, Harvard Medical School, Boston, Mass.

Received for publication Dec. 5, 1995; accepted for publication Feb. 26, 1996.

J Thorac Cardiovase Surg 1996;112:1117-9

Copyright $\odot 1996$ by Mosby-Year Book, Inc.

$0022-5223 / 96 \$ 5.00+0 \quad \mathbf{1 2 / 5 4 / 7 3 1 0 1}$ valve regurgitation (as great as $50 \%$ ) than do patients with Down syndrome (as great as $10 \%$ ). ${ }^{2}$ This difference may be caused primarily by tissue scarcity, deficiency of the superior or inferior bridging leaflets, or both. On the basis of these observations, we recently developed a modified surgical technique for reconstruction of the tissue-deficient bridging leaflets of the mitral valve, with the objective of decreasing the prevalence of postoperative regurgitation in this difficult subset of cases.

In the repair of CAVC, we prefer to close the atrioventricular septal defect with a single glutaraldehyde-preserved pericardial patch. To avoid iatrogenic regurgitation of the mitral valve, the tricuspid valve, or both, it is imperative not to use too wide a patch. After assessment 